Yanakiev, Dimov, and Bachvarov, v.39:1, https://doi.org/10.11610/isij.3907 2018, 77-89

\title{
CONCEPTUALIZING THE ROLE OF SOCIETAL RESILIENCE IN COUNTERING HYBRID WARFARE
}

\author{
Yantsislav YANAKIEV, Petko DIMOV, and Daniel BACHVAROV
}

\begin{abstract}
No single tool is available to counter the diversity and complexity of hybrid threats, examined by the authors as a as a military strategy that blends conventional warfare, irregular warfare, and cyber warfare. The concept of hybrid warfare is used to describe the flexible and complex dynamics of the battlespace requiring a highly adaptable and resilient response. Reflecting on recent NATO policies and documents, this article looks into the importance of strengthening societal resilience, understood as the ability of a state, organization or society to absorb and recover from a shock.
\end{abstract}

Keywords: Hybrid threats, hybrid warfare, societal resilience, social resilience, crisis management, disaster response, comprehensive approach, civil-military interoperability, interagency cooperation, risk reduction.

\section{Introduction}

The international regulatory mechanisms, established during an era of state-on-state conflict, have been progressively challenged throughout crises and conflicts of the late $20^{\text {th }}$ and early $21^{\text {st }}$ Century. The spectrum and geographic span of future conflicts have amplified, with an increasing blurring between the lines of conventional, irregular and hybrid activities that target society, cultural boundaries and ideology as a means of creating instability. ${ }^{1}$

Military capabilities and initiatives such as the NATO's Readiness Action Plan seek to support core collective defence tasks at a strategic level. However, more is needed to build resilient bonds between the Alliance, State Governance, Security Forces and Society. In nowadays security environment, countering such threats more than ever requires a full range of capabilities, military and civilian, and active interagency cooperation, as well as with the private sector. It also requires a deeper cooperation and engagement of NATO partners and other international bodies and continuously updated situational awareness. ${ }^{12}$ 
Societal Resilience is an essential basis for credible deterrence and effective fulfilment of the Alliance's core tasks. At the Warsaw Summit, in July 2016, the NATO Heads of State and Government made a commitment to continue to enhance NATO's resilience and to maintain and further develop the Alliance's individual and collective capacity to resist any form of armed attack. In addition, NATO Heads of State and Government welcomed the Resilience Guidelines approved by defence ministers in June 2016, which included the need for assessment and the development of plans for the continuity of government, continuity of essential services, security of critical civilian infrastructure, and support to military forces with civilian means. ${ }^{10}$

Security threats to nations and society can take many forms ranging from the conventional state on state conflict through to large scale man-made or natural disaster. ${ }^{13}$

Societal Resilience represents the ability of a state, organization or society to absorb and recover from a shock. In this way, resilience is a measure of the state's institutions' agility and is a fundamental factor in retaining social stability. ${ }^{2}$

At the national level, societal resilience has a key role to play especially as the crisis will always comprise a human element and will stretch the fabric of society. As societal demographics change and culture and ideological foundations migrate as a result of a more globalized society, social identity and cohesiveness can become fragmented offering opportunities for exploitation, especially by non-state actors, and perpetrators of terror and hybrid warfare. State's institutions and society protecting mechanisms, therefore, have a vital role to play in contributing to overall state and Alliance resilience in the future, enhancing and reinforcing the triumvirate relationship between governance, the providers of security and society itself. ${ }^{7}$

The goal of this article is to conceptualize the role of societal resilience in countering emerging security threats, including hybrid ones.

The paper covers the following topics:

- different perspectives of societal resilience concept definition and development;

- political and legal implications of societal resilience;

- hybrid strategies focused on societal vulnerabilities;

- measuring social resilience;

- SWOT analysis: resilience of the Bulgarian society;

- approaches to manage \& enhance societal resilience as a means to counter future threats. 


\section{Defining the Concept of Resilience}

Defining the Concept requires a proper consideration of the social resilience from different points of view as it follows:

- Psychological resilience perspective is defined as an individual's ability to successfully adapt to life tasks in the face of social disadvantage or highly adverse conditions of the hybrid war;

- Community resilience perspective is understood as the ability to anticipate risk, limit impact, and bounce back rapidly through survival, adaptability, evolution, and growth in the face of turbulent change. Resilient communities are not only prepared to prevent or minimize the loss or damage to life, property, and the environment, but they also have the ability to quickly return citizens to work, reopen businesses, and restore other essential services needed for a full and timely economic recovery; ${ }^{6}$

- Ecological and Socio-Ecological Resilience Perspectives is defined as the ability of an ecosystem to respond to a perturbation or disturbance by resisting damage and recovering quickly. Such perturbations and disturbances can include events such as fires, flooding, windstorms, insect population explosions, and human activities such as deforestation, fracking of the ground for oil extraction, pesticide sprayed in soil, and the introduction of exotic plant or animal species. Disturbances of sufficient magnitude or duration can profoundly affect an ecosystem and may force an ecosystem to reach a threshold beyond which a different regime of processes and structures predominates. $^{4}$

In addition to research on social-ecological systems, many social scientists have employed the broader concept of vulnerability to examine both the magnitude of a disruption that a social community can absorb and the likely speed of its recovery when confronted with stress. The degree of vulnerability is depicted as related to both the nature of the stress and the resilience of the system. Stress is considered external to the system and is characterized by a disturbance or shock relative to a threshold, whereas resilience is portrayed as an internal capacity of the system to cope with and adapt to a stress;

- Organizational and Institutional Perspective of resilience is defined as the ability of an organization or an institution to anticipate, prepare for, and respond and adapt to incremental change and sudden disruptions in order to survive and prosper; 
Based on a critical review of recently published literature on the issue, Markus and Sakdapolrak propose to define social resilience as being comprised of three dimensions:

1. Coping capacities - the ability of social actors to cope with and overcome all kinds of adversities;

2. Adaptive capacities - the ability to learn from past experiences and adjust to future challenges in the everyday life;

3. Transformative capacities - the ability to craft sets of institutions that foster individual welfare and sustainable societal robustness towards future crises. ${ }^{9}$

To summarize, most definitions of resilience outline one or two perspectives; 1) reactive recovery, and/or 2) stability after traumatic events, such as natural disaster. In addition, societal resilience is not only a dynamic and relational concept but also a deeply political one. Finally, one can identify adaptive and transformative dimensions of societal resilience.

\section{Political and Legal Implications of Societal Resilience}

Resilient systems and organizations need to maintain some functionality and control while under attack. To this end three elements are critical:

- Capacity to work under downgraded conditions

- Ability to recover quickly;

- Readiness to learn from experienced attacks.

NATO's Allied Command Transformation (ACT) has identified four focus areas with the potential to enhancing resilience:

- Identifying key vulnerabilities and associated risks - this enables governments to develop adequate responses and mechanisms to manage consequences orchestrating all suitable instruments of power - both nationally and internationally.

- Synchronizing cross-governmental decision making - countering hybrid threats demands a different, cross-governmental approach employment of security mechanisms than in the past. Political and military decision-makers need to be able to out-manoeuvre opponents attacking own centres of gravity.

- Building military sustainability and civil preparedness - the civil population is not only a potential victim; at the same time, it is a critical source of strength, of resilience. Civil preparedness enables military sustainability, while military capabilities protect the population and its prosperity. 
- Balancing the allocation of available resources - enhancing the links between the civil, private and military sector will enable cost-sharing and benefit resilience at the same time. It provides for developing means of mitigation, such as diversification of supply, resource, and service. ${ }^{6}$

In brief, first of all, it is important to implement broad assessment of the nature, aspects, and appearance of future threats, and the need for new military and nonmilitary capabilities to counter them. In addition, legal and doctrinal limitations and gaps for the application of a comprehensive institutional approach to capabilities development countering new threats should be carried out. Last but not least, NATO Nations and Partners regional cooperation mechanisms in enhancing societal resilience are needed.

\section{Hybrid Strategies focused on Societal Vulnerabilities}

For the purpose of this paper, we define vulnerability as incapacity to anticipate, cope with, resist to, adapt to and recover from hazards. Vulnerable entities are either not resistant, i.e. not capable to withstand the shock (without adapting); and/or not resilient, i.e. not capable to absorb the shock and adapt to come back to an acceptable state.

The hybrid threat is a phenomenon resulting from convergence and interconnection of different elements, which together form a more complex and multidimensional threat. Hybrid conflict and hybrid warfare are two specific categories, whereby some hybrid tactics are used by a state to achieve its strategic ends. ${ }^{3}$

As a rule hybrid strategies focus on previously identified societal vulnerabilities (e.g. week/failed state, internal conflicts, divided society, lack of political consent about the future of the society, corruption, inefficient law enforcement, lack of natural resources and dependency of foreign states, etc.)

\section{Hybrid Warfare and Societal Resilience}

Hybrid warfare is a potent, complex variation of warfare that simultaneously involves state and non-state actors, with the use of conventional and unconventional means of warfare that are not limited to the battlefield or to a particular physical territory. The decision of the war/conflict is searched for primarily at non-military centers of gravity. Any space available may be engaged. This includes traditional and modern media instruments. Non-state actor's involvement includes militias, transnational criminal groups, or terrorist networks of strategic nature. Hybrid concepts and strategies target vulnerabilities - from cyber-attacks on critical information systems, through the disruption of critical services, such as energy supplies or financial services, to undermining public trust in government institutions or social cohesion. Hybrid warfare appears 
to be a construct of vaguely connected elements, but in reality, the pieces are a part of an intended mosaic. The diversity of hybrid tactics masks the thoroughly planned order behind the spectrum of tools used and the effects being achieved.

The hybrid threat is a phenomenon resulting from convergence and interconnection of different elements, which together form a more complex and multidimensional threat. Hybrid conflict and hybrid warfare are two specific categories, whereby some hybrid tactics are used by a state to achieve its strategic ends. ${ }^{3}$

Building societal resilience has become a strategic task. By building up pre-crisis resilience to deal with hybrid security challenges, we will be better able to resist, recover, and to assign responsibility to an aggressor or a nation.

Resilience should be built in areas such as cyber security, critical infrastructure, protecting the financial system from illicit use and efforts to counter violent extremism and radicalization.

To summarize, first of all, hybrid warfare is the future of warfare. Building societal resilience is the key factor in countering hybrid warfare and mitigating societal vulnerabilities.

Intelligence and security services have a particular role in countering hybrid tactics. In addition, all dimensions and levels of societal resilience should be considered (individual, team, organization/institution, community, and society). Moreover, main challenges related to countering hybrid warfare are: (1) establishing responsibility and intentionality of adversary actions; (2) International law enforcement and effective global governance.

\section{Measuring Societal Resilience}

An important step in identifying the most appropriate way to measure societal resilience for a particular context is to look at which elements of resilience are included in the measure. ${ }^{11}$

A. Measuring well-being before and after a threat - The assumption is that the degree of resilience of a particular household, community or population can also be determined partially by assessing the extent to which they can maintain general well-being in the event of a threat. These measurements typically rely on more traditional development indicators related to livelihoods, economic situation, human capital, nutrition, etc. These measures of well-being do not necessarily have to be related to disasters, disaster resilience, disaster risks, and so on. A number of general development indicators can typically be used to compare well-being over time. To be meaningful for assessing resilience, measurements are required at least once prior to and once after a disaster;

B. Measuring vulnerability - To measure vulnerability, we must determine how exposed people are to threats and how likely it is that they get harmed; 
C. Measuring resilience capacities to cope, adapt, and transform in case of a threat the capacity for resilience in case of a threat is typically regarded to be at the core of the resilience concept as well as of resilience measurements. Resilience capacities depend largely on subjective or empiric characteristics and a certain set of assumptions about resilience;

D. Measuring threat-related shocks, losses, and stress;

E. Measuring the reaction to and recovery from threats - To measure the response and recovery after a disaster, we must go beyond the assumed capacity to absorb, adapt and transform;

F. Measuring program results. Program results are different from more general measurements of resilience in two ways:

a) They focus on more narrow elements of resilience (e.g. on a specific resilience capacity or a specific sector or type of disaster);

b) They contain more details on the activity and output level than broader measurements, to better reflect the details of a program intervention.

According to Resilient Organizations Research Group, organizations' resilience can be defined as 13 resilience indicators as follows: ${ }^{8}$

1. Evaluate leadership in the Alliance, ensure good governance and make the right decisions by state and military leaders during hybrid threats and crises.

2. Evaluate the commitment of NATO members to the mission and goals of the North Atlantic Alliance.

3. Raising awareness and the existence of an early warning system between institutions.

4. The existence of clearly delegated decision-making powers in state and allied structures.

5. Assess the level of innovations used and apply a creative approach to problemsolving.

6. Assess the effectiveness of NATO partnerships and understand the links that can be used in crisis response planning.

7. The availability of knowledge, storage and access to expert information on hybrid counteraction.

8. Breaking Silos - Existence of separating social, cultural and behavioural barriers that may lead to potential problems and disruptions between different nations.

9. Assess the internal resources that can be mobilized in NATO structures to deal with all sorts of hybrid threats. 
10. Unity of purpose, how many different NATO members follow the priorities and minimum operational requirements of the organization.

11. Presence of proactive strategic and operational readiness to respond to early warning signals from changes in the internal and external environment before the escalation of the crisis.

12. To what extent were developed strategies, concepts and plans for managing social vulnerability in relation to the new security environment?

13. The existence of stress testing plans and simulations for validation of plans.

The combination of all these parameters provides a general picture of the ability to cope with crises and survival in hybrid warfare.

\section{SWOT analysis: A General Idea about the Resilience of the Bulgarian Society}

In order to make a precise assessment of the resilience of the society, it is necessary to thoroughly compare and understand both the strengths and weaknesses, as well as the opportunities that exist together within the society. After making a thorough comparison and estimation of those criteria and knowing the possible threats, we can develop a more efficient approach towards building societal resilience against emerging security threats.

This paper has no any pretenses to present a thorough assessment of the level of resilience of the Bulgarian society towards hybrid threats. It just summarizes some views of the authors as a basis for further comprehensive research that is needed. The following rows present the summary of identified strengths, weaknesses, opportunities, as well as threats.

\section{Strengths}

(1) Among the most important strengths is the membership in NATO and EU and the existing regional security cooperation in South Eastern Europe (SEE);

(2) Existing interagency cooperation at the national level is also an important factor that guarantees enhanced resilience;

(3) The next strength is the stable macroeconomic environment and low direct taxes.

\section{Weaknesses}

(1) One of the main weaknesses of the Bulgarian society is the lack of legal and political means for addressing hybrid warfare; 
(2) The character of the hybrid warfare creates difficulties in identifying adversary actions and main actors, which requires an improvement of the early warning system;

(3) Among the most important weaknesses is the unstable society which is divided into different sub-groups (high level of poverty, political, interethnic and religious tensions, high level of corruption, lack of trust in the state institutions and politics, etc.)

(4) Dependence on natural resources also significantly reduces the social sustainability of our society.

\section{Opportunities}

(1) To consider every possible change in the national security policy and doctrine;

(2) To develop a better comprehensive, whole of government approach towards the resilience of the society;

(3) An improvement of coordination among government agencies, non-governmental organizations, and private individuals;

(4) Joint, multinational, and interagency Education and Training (E\&T) for crisis management to build a hybrid mindset is needed;

(5) Blending all actors and available instruments: military forces, diplomacy, humanitarian aid, political processes, economic development, and technology.

\section{Threats}

(1) To consider every possible change in the national security policy and doctrine; (1) Among the most dangerous threats that can lead to potential problems is continuing disintegration of the society and widening of the areas of societal vulnerabilities;

(2) The lack of a political will to build an effective early warning system to recognize hybrid strategies is another important factor contributing to the reduction of societal resilience;

(3) Inadequate and insufficient legal and doctrinal basis to counter hybrid strategies further weakens the sustainability of our society;

(4) The lack of effective interagency and international cooperation leads to weakness in countering hybrid threats;

(5) Inadequate policy responses due to underestimation of hybrid threats. 


\section{Approaches to Manage and Enhance Societal Resilience as a Means to Counter Future Threats}

In order to make a precise assessment of the resilience of the society, it is necessary to thoroughly compare and understand both the strengths and weaknesses, as well as the opportunities that exist together within the society. After making a thorough comparison and estimation of those criteria and knowing the possible threats, we can develop a more efficient approach towards building societal resilience against emerging security threats.

Future threats require dealing with the unknown: future circumstances, events, or outcomes that are impossible to predict and to plan for. This requires the development of proactive government-led comprehensive approaches to better develop all of the social strategies aimed at managing risks and building a resilient society.

These strategies must be developed in a way to define the best directions for the concentration of resources from different stakeholders to counter hybrid threats (government, civil society, the private sector and individual citizens). Public-private cooperation on security, the development, and modernization of civilian and military capabilities need to be improved.

Military forces, and especially deployed troops in times of war, depending on the civilian sector for transport, communications or basic supplies such as food and water, to fulfil their missions. Military efforts to defend Alliance territory and populations, therefore, need to be complemented by robust civil preparedness. However, civil assets can be vulnerable to external attack and internal disruption in times of peace and of war. By reducing these vulnerabilities, reduces the risk of a potential attack, reinforcing its deterrence. A high level of resilience is, therefore, an essential component of a credible deterrence.

The development of innovative legal concepts and frameworks is one of the best ways to address hybrid threats adequately.

In addition, government organizations need to be open to innovative legal concepts and alternative approaches in order to address hybrid threats adequately.

Choosing the new resilient instruments over the status quo might increase the need for alternative approaches (i.e. confidence building measures, law enforcement cooperation and mutual legal assistance).

The existing stove pipe security institutions might not be adequate anymore. Thus, it is necessary to expand the missions of current institutions in the security sector (i.e. new authorities for intelligence and counterintelligence agencies and armed forces, boosting strategic communication) or creating new organizations. 
All this can be achieved with the help of innovative methods in education, training, exercises, and evaluation in countering hybrid warfare.

The vulnerabilities we need to fight with are numerous, complex and multidirectional. They can arise from military challenges, hybrid warfare, but also from natural disasters such as floods, fires, and earthquakes. Our work to improve resilience is not specific to any single vulnerability. It contributes to protecting citizens from all potential hazards.

\section{Conclusions}

As it was emphasized in the beginning, the goal of this paper is to stimulate an expert discussion on the role of societal resilience in countering emerging security threats, including hybrid ones. We consider important to encourage an expert discussion on these topics because building societal resilience has become a strategic task when countering hybrid warfare. In this regard, it is important to restate that societal resilience is a dynamic and relational concept, as well as profoundly political one.

Hybrid strategies can be successful only when they are focused on existing societal vulnerabilities. Therefore, is it vital for any society to identify and monitor its strengths, weaknesses or vulnerabilities, opportunities for reaction, or even pro-active measures and potential threats well in advance before the escalation of the crisis. In addition, in order to recognize the most appropriate way to counter emerging security threats, it is vital to develop and apply robust mechanisms and metrics to measure societal resilience.

In general hybrid strategies are very difficult to be identified. Usually, they are longlasting, complex and multidimensional processes targeting social identity, values, and norms and beliefs, public perceptions and attitudes, etc. As a practice they are difficult, if not impossible, to predict. For that reason, our preparedness should be concentrated on dealing with unknown-unknowns. This means a substantial change in the organization, structure, functions, and operation of the security sector. Obviously, the existing stovepipe organization of the security sector institutions is not effective enough to counter hybrid warfare. There is clear need for improved interagency cooperation and coordination, as well as the commitment of private sector, civil society, and even each individual citizen. In addition, all dimensions and levels of societal resilience should be considered (individual, team, organization/institution, community, and society). Finally, in order to be successful against hybrid strategies, the key words are whole of government and whole of society approach. 


\section{Notes}

1. Alastair McAslan, "Organisational Resilience. Understanding the Concept and its Application," A Strawman Paper, Adelaide, Australia, Torrens Resilience Institute, 3 May 2010, accessed April 4, 2018, http://www.flinders.edu.au/centresfiles/TRI/pdfs/organisational\%20resilience.pdf.

2. Birutė Pitrènaitè-Žilènienè, Andrea Carosi, and Paolo Vallesi, "Enhancing Societal Resilience against Disasters: Engaging the Public via Social Technologies," Social Technologies 4, no. 2 (2014): 318-332.

3. Eve Hunter and Piret Pernik, "The Challenges of Hybrid Warfare," Tallinn, Estonia: International Centre for Defence and Security, April 2015, accessed April 4, 2018, www.icds.ee/fileadmin/media/icds.ee/failid/Eve_Hunter_Piret_Pernik__Challenges_of_Hybrid_Warfare.pdf.

4. Richard Haigh and Amaratunga Dilanthi, "Moving from 2015 to 2030: challenges and opportunities for higher education in developing resilience to disasters," in Proceedings of the 8th International Conference of Faculty of Architecture Research Unit (FARU), University of Moratuwa, Colombo, Sri Lanka, 2015, p. 215225, accessed on June 17, 2017, http://www.eprints.hud.ac.uk/27111/.

5. John R. Davis Jr., "Continued evolution of hybrid threats. The Russian Hybrid Threat Construct and the Need for Innovation," The Three Swords Magazine 28 (2015): 19-25.

6. John T. Cacioppo, Harry T. Reis, and Alex J. Zautra, "Social Resilience. The Value of Social Fitness with an Application to the Military," American Psychological Association 66, no. 1 (January 2011): 43-51, https://doi.org/10.1037/ a0021419.

7. Judy Burnside-Lawry and Peter Rogers, "Communication research to build societal resilience," International Journal of Disaster Resilience in the Built Environment 7, no. 1 (2016): 2-3, https://dx.doi.org/ 10.1108/IJDRBE-02-2016-0005.

8. Katharina Näswall, Joana Kuntz, Morgana Hodliffe, and Sanna Malinen, Employee Resilience Scale (EmpRes) Measurement Properties, Resilient Organisations Research Report 2015/04 (New Zealand: Resilient Organisations Research Programme, August 2015).

9. Markus Keck and Patrick Sakdapolrak, "What is social resilience? Lessons learned and ways forward," ERDCUNDE 67, no. 1 (2013): 5-19, https://doi.org/10.3112/erdkunde.2013.01.02; Niru Nirupama, T. Popper, and A. Quirke, "Role of social resilience in mitigating disasters," International Journal of Disaster Resilience in the Built Environment 6, no. 3 (2015): 363-377, https://doi.org/10.1108/IJDRBE-09-2013-0039.

10. Warsaw Summit Communiqué Issued by the Heads of State and Government participating in the meeting of the North Atlantic Council in Warsaw 8-9 July 2016, Press Release (2016) 100, accessed April 4, 2018, https://www.nato.int/cps/en/ natohq/official_texts_133169.htm. 
11. Nebil Achour, Efthimia Pantzartzis, Federica Pascale, and Andrew D. F. Price, "Integration of Resilience and Sustainability: From Theory to Application," International Journal of Disaster Resilience in the Built Environment 6, no. 3 (2015): 347-362, https://doi.org/10.1108/IJDRBE-05-2013-0016.

12. "Enhancing Resilience through Civil Preparedness, NATO Baseline Requirements for National Resilience and Associated Resilience Guidelines," Notice, North Atlantic Council, Civil Emergency Planning Committee, September 7, 2016.

13. "Compendium of Baseline Requirements, Resilience Guidelines, Initial Evaluation Criteria and Initial Best Practices," North Atlantic Council, Civil Protection Group, Transport Group, Joint Health, Agriculture and Food Group, Industrial Resources and Communications Services Group, October 4, 2016.

\section{About the Authors}

Prof. Yantsislav YANAKIEV - see the CV on p. 10 of in the Editorial article of this volume, https://doi.org/10.11610/isij.3900.

Lieutenant Colonel Petko DIMOV, PhD, is Chief Assistant in the "Research and Innovation in the Military Technology" Section of the Defence Advanced Research Institute (DARI) in G. S. Rakovski National Defence College.

Major Daniel BACHVAROV is Assistant Professor in the "Research and Innovation in the Military Technology" Section of the Defence Advanced Research Institute (DARI) in G. S. Rakovski National Defence College. 